\title{
Morfogénesis in vitro de brotes adventicios del pinabete mexicano Pseudotsuga menziesii (Mirb.) Franco
}

\section{In vitro adventitious shoot morphogenesis of the Mexican Douglas-fir Pseudotsuga menziesii (Mirb.) Franco}

Florencia García Campusano ${ }^{1}$, Guadalupe Monjarás González ${ }^{2}$, Gema Galindo Flores ${ }^{3}$, Alejandro Ponce Mendoza ${ }^{1,4}$, Víctor Manuel Chávez Ávila ${ }^{5}$ y Judith Márquez Guzmán ${ }^{6 *}$

\begin{abstract}
Pseudotsuga menziesii is a conifer of ecological and economic importance worldwide. Due to the small size of its native populations in Mexico, natural regeneration in this species is poor, therefore in vitro cultivation is considered as an alternative strategy for its propagation and conservation. The effect of two combinations of auxins and cytokinins in the induction of adventitious shoots was compared. Mature embryos were grown on solid Schenk and Hildebrandt (SH) medium containing $0.53 / 13.32 \mu \mathrm{M}$ of 1-naphthalene acetic acid (NAA) / 6-benzyladenine (BA) or 2,4-dichlorophenoxyacetic acid (2,4-D) / kinetin (K). The buds were formed via direct organogenesis in the hypocotyl and cotyledons. After 90 and 130 days of culture, the organogenic capacity was higher in NAA / BA and extended for a longer period than in 2,4-D / K, although the latter the shoots were more vigorous. Histological analysis showed the sequential appearance of distinct promeristemoids and meristemoides on the surface far from the medium, whereas wide meristematic zones and meristematic nodules formed in the tissues in contact with the medium, which gave rise to the outbreaks, was detected in both treatments. Because the buds formed included cells of the epidermis and embryonic subepidermis a multicellular origin is proposed. This work allowed us to better understand the events associated with direct organogenesis that may impact on the consolidation of regeneration protocols and future improvement strategies.
\end{abstract}

Key words: Auxins, caulogenesis, ciokinines, tissue culture, ontogeny, Pseudotsuga.

\begin{abstract}
Resumen
Pseudotsuga menziesii es una conífera de importancia ecológica y económica a nivel mundial. Debido al reducido tamaño de sus poblaciones nativas en México, la especie enfrenta serias dificultades para su regeneración natural, por lo que el cultivo in vitro se plantea como estrategia alternativa para su propagación y conservación. Se comparó el efecto de dos combinaciones de auxinas y citocininas en la inducción de brotes adventicios. Se cultivaron embriones maduros en medio Schenk y Hildebrandt (SH) adicionado con 0.53/13.32 ị M de ácido 1-naftalenacético (ANA)/ 6-benciladenina (BA) o ácido 2,4-diclorofenoxiacético (2,4-D) / cinetina (K). Los brotes se formaron vía organogénesis directa en el hipocotilo y en cotiledones. Después de los 90 y 130 días de cultivo, la capacidad organogénica fue mayor en ANA/BA y se extendió por un período más largo que en 2,4-D/K, aunque este último los brotes fueron más vigorosos. Mediante un análisis histológico se detectó, en ambos tratamientos, la aparición secuencial de promeristemoides, meristemoides en la superficie alejada del medio, así como amplias zonas meristemáticas y nódulos meristemáticos en los tejidos en contacto con el medio, que dieron lugar a los brotes. Debido a que los brotes formados incluyeron células de la epidermis y subepidermis embrionaria se propone un origen multicelular. Este trabajo permitió comprender mejor los eventos asociados a la organogénesis directa que pueden impactar en la consolidación de los protocolos de regeneración y futuras estrategias de mejoramiento. Palabras clave: Auxinas, caulogénesis, citocininas, cultivo de tejidos, ontogenia, Pseudotsuga.
\end{abstract}

Fecha de recepción/Reception date: 14 de marzo de 2019

Fecha de aceptación/Acceptance date: 17 de junio de 2019

\footnotetext{
${ }^{1}$ Cenid-Comef, Instituto Nacional de Investigaciones Forestales, Agrícolas y Pecuarias. México.

${ }^{2}$ Instituto Tecnológico Superior de San Martín Texmelucan. México.

${ }^{3}$ Centro de Investigación en Ciencias Biológicas, Universidad Autónoma de Tlaxcala. México.

${ }^{4}$ Comisión Nacional Para el Conocimiento y Uso de la Biodiversidad en México. México.

${ }^{5}$ Laboratorio de Cultivo de Tejidos Vegetales Jardín Botánico del Instituto de Biología, Universidad Nacional Autónoma de México. México.

${ }^{6}$ Departamento de Biología Comparada, Laboratorio de Desarrollo en Plantas, Facultad de Ciencias, Universidad Nacional Autónoma de México. México.

*Autor por correspondencia: judith.marquez@ciencias.unam.mx
} 


\section{Introducción}

Pseudotsuga menziesii (Mirb.) Franco, conocido en México como pinabete, es una conífera de importancia ecológica y económica, que se extiende desde Columbia Británica en Canadá hasta el centro de México (Hermann y Lavender 1990; Gugger et al., 2011). En México, las poblaciones naturales de esta especie conforman el límite sur de su área de distribución y crecen en rodales pequeños y fragmentados (Vargas et al., 2004). La distribución disyunta, aunado a la pérdida de bosques por cambio en el uso de suelo, ha reducido el número de individuos que participan en la reproducción, lo que ha resultado en una baja regeneración natural, por la baja producción y fertilidad de las semillas, así como de la tasa de reclutamiento de plántulas, y finalmente en altos niveles de endogamia en las poblaciones (Mápula et al., 1996; Zavala y Méndez, 1996; Juárez et al., 2006; Velasco et al., 2007), particularmente hacia el límite sur de su distribución: Hidalgo, Tlaxcala, Puebla y Oaxaca. Por ello, se le cataloga como especie sujeta a protección especial en la Norma Oficial Mexicana (NOM-059-SEMARNAT-2010) (Semarnat, 2010), y se le considera especie prioritaria en los programas de conservación y reforestación en el país (Vargas et al., 2004) que favorezcan su regeneración, así como alternativas para su aprovechamiento sustentable.

El cultivo in vitro de tejidos vegetales ofrece importantes perspectivas para la propagación de especies forestales. Las técnicas representan el fundamento de la investigación en la propagación, mejoramiento y conservación de germoplasma. No obstante, para las coníferas sigue siendo complicado y el éxito con frecuencia se restringe a genotipos particulares dentro de las especies (Bonga, 2015). La propagación de $P$. menziesii en esta modalidad se ha logrado mediante el uso de explantes originados de poblaciones nativas de Estados Unidos de América; se han obtenido diversos protocolos para la regeneración de brotes adventicios a partir del cultivo de embriones y cotiledones, por organogénesis directa (Cheng y Voqui, 1977; Cheah y Cheng, 1978) e indirecta (Winton y Verhagen, 1977), así como la proliferación y alargamientos de brotes apicales y axilares (Gupta y Durzan, 1985) y embriones somáticos (Durzan y Gupta, 1987). 
Sin embargo, no ha sido posible transferir estos protocolos para la propagación in vitro de genotipos de procedencias mexicanas de la especie en cuestión, y el éxito a la fecha ha sido muy limitado. A partir del cultivo de embriones cigóticos maduros de semillas procedentes de dos poblaciones naturales en México (Tlaxco y Terrenate, en el estado de Tlaxcala), se logró obtener brotes adventicios al hacer doce combinaciones de los reguladores de crecimiento 6-benciladenina (BA) con ácido naftalenacético (ANA) y cinetina (K) con ácido 2,4-diclorofenoxiacético (2,4-D), cuyas concentraciones abarcaron de 0 a $0.5 \mathrm{mgL}^{-1}$ de las auxinas y de 1 a $5 \mathrm{mg} \mathrm{L}^{-1}$ de citocininas. El enraizamiento fue esporádico, lo que restringió la implementación de la tecnología de propagación a mayor escala (Galindo et al., 2000). Posteriormente, se llegó a la formación de callo y estructuras de tipo embrionario a partir del cultivo de embriones cigóticos maduros, aunque no mostraron evidencias histológicas, ni el desarrollo de plántulas a partir de ellas (Carrillo et al., 2011). La amplia variabilidad en la respuesta morfogenética demuestra que aún se conoce muy poco acerca de la interacción de los diferentes factores del cultivo en la respuesta morfogenética de los explantes, en particular en lo que respecta a la naturaleza de los reguladores de crecimiento.

Debido al interés por consolidar un sistema de propagación in vitro que permita la regeneración de genotipos mexicanos de $P$. menziesii, en el presente trabajo se buscó caracterizar y comparar la respuesta morfogenética de embriones cigóticos maduros expuestos a dos combinaciones de reguladores de crecimiento; se evaluó la capacidad para inducir brotes adventicios, así como el patrón de desarrollo de los mismos respecto al tipo de tejido involucrado y el efecto de su distancia con el medio de cultivo. Mediante un análisis estructural se logró profundizar en la comprensión del origen y de los eventos celulares que ocurren previos a la diferenciación de los brotes, y que sirven para explicar el efecto que tienen los reguladores de crecimiento en mantener la capacidad organogénica. 


\section{Materiales y Métodos}

\section{Procedencia del material biológico}

Se utilizaron 200 semillas maduras de $P$. menziesii donadas por el Instituto Nacional de Investigaciones Forestales, Agrícolas y Pecuarias (INIFAP). Este material se recolectó en bosques de Terrenate, Tlaxcala de un número indeterminado de árboles en 1996. Se almacenaron en bolsas de plástico en un cuarto frío a $4{ }^{\circ} \mathrm{C}$ hasta su uso.

\section{Pretratamiento de las semillas}

Las semillas se limpiaron y desinfectaron bajo condiciones asépticas mediante su inmersión en: 1) $\mathrm{H}_{2} \mathrm{O}_{2}$ al $30 \%(\mathrm{v} / \mathrm{v})$ durante 60 min; 2) Benomyl $\left(0.5 \mathrm{~g} \mathrm{~L}^{-1}\right)$ durante 24 h; Cloranfenicol (20 mg L ${ }^{-1}$ ) por $45 \mathrm{~min}$; 3) cloro comercial al $15 \%(\mathrm{v} / \mathrm{v})(6 \% \mathrm{NaOCl})$ por $60 \mathrm{~min} ; 4)$ en $\mathrm{H}_{2} \mathrm{O}_{2}$ al $1 \%(\mathrm{v} / \mathrm{v})$ por $48 \mathrm{~h}$. Entre cada paso, las semillas se enjuagaron tres veces con abundante agua destilada estéril. Bajo condiciones de asepsia se eliminó la cubierta seminal y se extrajeron los megagametofitos, los cuales se enjuagaron con una solución de cloro comercial al $15 \%(\mathrm{v} / \mathrm{v})$ por 60 segundos, seguido de tres enjuagues en agua destilada estéril, antes de disectar el embrión. Previo a la siembra de los embriones, se sumergieron en una solución de cloranfenicol $\left(60 \mathrm{mg} \mathrm{L}^{-1}\right)$.

\section{Inducción de brotes adventicios}

Este procedimiento se basó en el protocolo descrito por Galindo et al. (2000). Se utilizó medio SH (Schenk and Hildebrandt, 1972) suplementado con sacarosa (30 g ${ }^{-1}$ ), solidificado con Phytagel ${ }^{\circledR}(0.6 \%)$ y con una de dos combinaciones de reguladores de crecimiento: ANA/BA y 2,4-D/K a 0.53/13.32 $\mu \mathrm{M}$. El pH del medio se ajustó a 5.7-5.8, antes de esterilizar a $1.5 \mathrm{~kg} / \mathrm{cm}^{2}, 121^{\circ} \mathrm{C}, 15 \mathrm{~min}$ en una autoclave Felisa FE-399. Los embriones cigóticos maduros se acomodaron de forma horizontal en cajas de Petri y se incubaron por 30 días en una cámara de crecimiento Forma Scientific modelo 3740 , a $23 \pm 1^{\circ} \mathrm{C}$, con un 
fotoperíodo de $16 \mathrm{~h}$ luz y $8 \mathrm{~h}$ de oscuridad, a una PPFD de $46-48 \mu \mathrm{molm}^{-2} \mathrm{~s}^{-1}$. Para ambos tratamientos se pusieron diez embriones por caja de Petri con tres repeticiones.

\section{Desarrollo y elongación de brotes adventicios}

Después del período de inducción, los embriones se transfirieron a un medio de elongación, sin reguladores de crecimiento, el cual consistió de medio SH reducido al $50 \%$ de su concentración de componentes inorgánicos, suplementado con sacarosa (3 $\left.\mathrm{g} \mathrm{L}^{-1}\right)$, polivinilpirrolidona (PVP) $\left(250 \mathrm{mg} \mathrm{L}^{-1}\right)$, agente antivitrificante $\left(0.5 \mathrm{~g} \mathrm{~L}^{-1}\right)$ (SIGMA) y fue solidificado con Phytagel ${ }^{\circledR}(0.6 \%)$. Se incubaron bajo las condiciones antes mencionadas. Se realizaron subcultivos quincenales durante seis meses y se individualizaron los brotes una vez que rebasaron una longitud de $0.5 \mathrm{~mm}$, los cuales se resembraron sobre el mismo medio.

\section{Análisis estructural}

Con fines descriptivos, se tomó como referencia inicial al embrión maduro y su posición horizontal sobre el medio de cultivo, a partir del cual se definieron las siguientes zonas: superficie del embrión en contacto directo con el medio (SCM), superficie del embrión más alejada del medio (SAM): cotiledones (cot), el hipocotilo (hcot), el meristemo apical y la cofia.

Se analizaron de 5 a 10 embriones de cada tratamiento a los $0,3,6,10,12,14,16$, $22,30,45$ y 90 días de cultivo, mismos que se fijaron en formaldehido: ácido acético (FAA): alcohol: agua destilada, 10:5:50:35) durante un mínimo de $48 \mathrm{~h}$. Posteriormente, el material se enjuagó en agua destilada y se deshidrató de manera gradual en una serie de diluciones de alcohol etílico (al 30, 50, 70, 85, 96 y $100 \%$ ), y con la aplicación de cambios cada hora.

Para la infiltración con Paraplast ${ }^{\circledR}$, las muestras se sumergieron en xilol durante 10 min $y$ luego se transfirieron gradualmente a mezclas de xilol-Paraplast en 
proporciones de $3: 1,1: 1$ y $1: 3$, durante una hora cada una. Finalmente, se colocaron en Paraplast puro durante un mínimo de $24 \mathrm{~h}$ a $56^{\circ} \mathrm{C}$, para luego proceder a la inclusión. El tejido se seccionó a 6-8 $\mu \mathrm{m}$ con un microtomo de rotación American Optical 820 y después se tiñeron con safranina-verde rápido.

\section{Análisis de datos}

El número de brotes por embrión y formación de brotes de acuerdo a las zonas determinadas se evaluó a los 90 y 130 días. Los datos se analizaron mediante un GLM con una distribución de familia quasi Poisson. Para el GLM se utilizó la función ' $\mathrm{g} / \mathrm{m}$ '. El análisis Post-hoc de Tukey para los modelos de GLM se hizo con la función 'glht' del paquete 'multcomp'. Todos los análisis se hicieron mediante el programa R 2.14.0 (R Development Core Team, 2011).

\section{Resultados}

Al evaluar la respuesta de los explantes a los dos tratamientos, no se encontraron diferencias en el número de embriones que respondieron $(P<0.05)$ : en ANA/BA, 75.8 $\%$ formaron brotes, mientras $73.7 \%$ lo hicieron con 2,4-D/K (Cuadro 1). Para ambos tratamientos, el número de brotes con primordios foliares claramente diferenciados aumentó en el transcurso de 90 a 130 días, aunque solo fue significativamente mayor en los tratamientos con ANA/BA $(P<0.05)$, en los que el promedio de nueve brotes que se observó en inicio, se duplicó a los 130 días (Cuadro 1); en contraste, en 2,4$\mathrm{D} / \mathrm{K}$, prácticamente no se incrementaron a través del tiempo $(P<0.05)$. 
Cuadro 1. Promedio de brotes adventicios formados a partir del cultivo de embriones cigóticos maduros de Pseudotsuga menziesii (Mirb.) Franco después de 90 y 130 días tratados con 0.53/13.32 $\mu \mathrm{M}$ de ANA/BA o 2,4-D/K.

\begin{tabular}{l} 
Tratamiento $\begin{array}{c}\text { Embriones col } \\
\text { brotes }(\%)\end{array}$ \\
\cline { 3 - 6 }
\end{tabular}

Tanto los cotiledones como el hipocotilo aportaron un número similar de brotes, aunque en ANA/BA se contabilizaron más $(P<0.05)$. No obstante, los brotes formados a partir de embriones tratados con 2,4-D/K tuvieron una apariencia más vigorosa, al alargarse más rápidamente (Figura $1 \mathrm{~A}$ y $1 \mathrm{~B}$ ). 

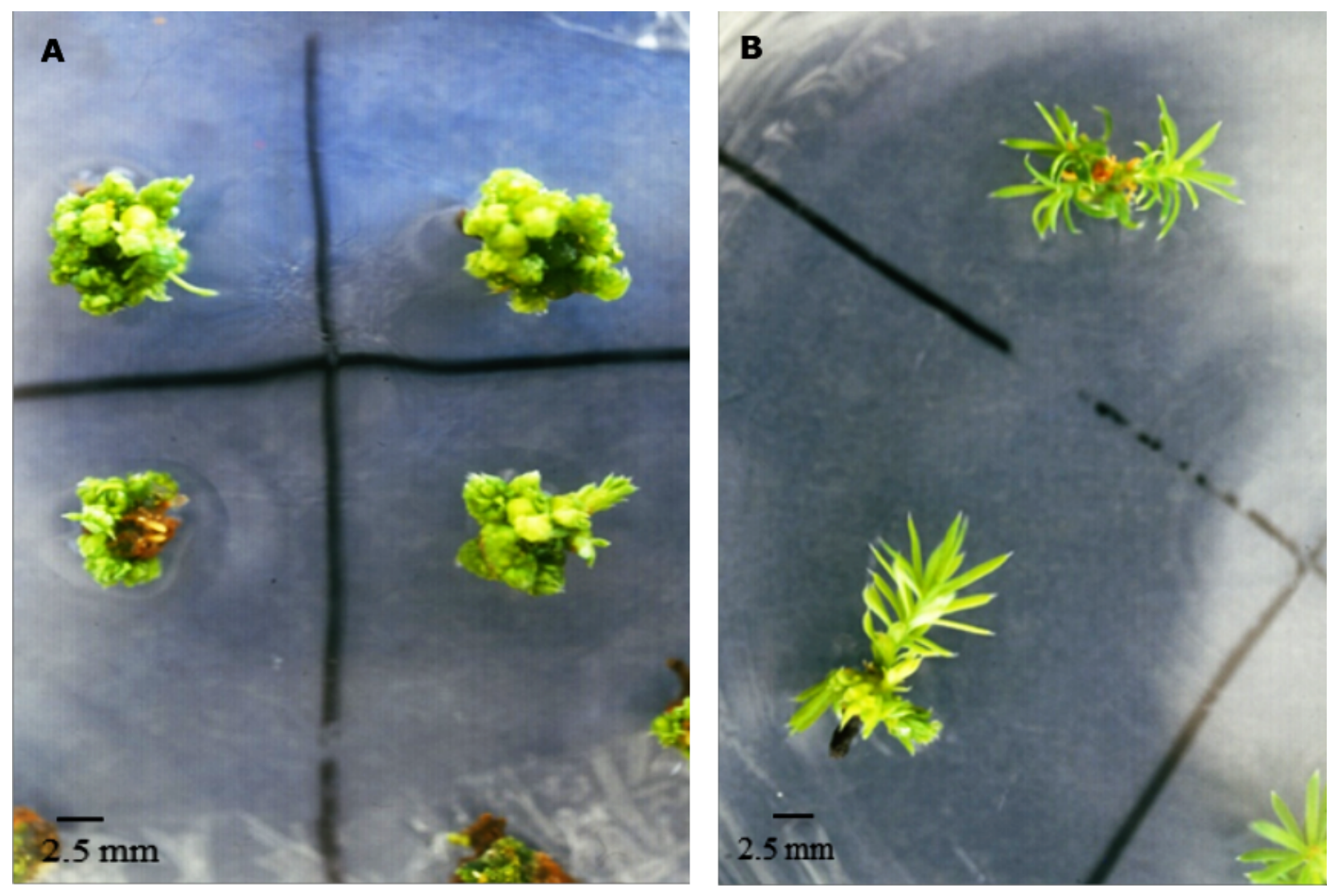

Figura 1. Brotes adventicios formados después de 130 días de cultivo tratados con $0.53 / 13.32 \mu \mathrm{M}$ de A) ANA/BA, o B) 2,4-D/K.

Por otra parte, se comparó el efecto de la distancia de los tejidos embrionarios sobre el medio de cultivo en su respuesta morfogenética. Se observó que el número de brotes adventicios formados a partir de los cotiledones e hipocotilo de la SCM fue similar para ambos tratamientos; aproximadamente $37 \%$ de los brotes que se desarrollaron en ANA/BA y $53 \%$ en $2,4-D / K$ se iniciaron de esta superficie. En ANA/BA se obtuvo un número significativamente mayor a partir de los tejidos de la SAM $(P<0.05)$ (Cuadro 2$)$. 
Cuadro 2. Influencia de la distancia del tejido del medio de cultivo sobre el número promedio de brotes formados en cotiledones e hipocotilo de embriones maduros de Pseudotsuga menziesii (Mirb.) Franco, a los 90 días de cultivo.

\begin{tabular}{ccc}
\hline Tratamiento de inducción & $\begin{array}{c}\text { Número promedio de } \\
\text { brotes /hipocotilo }\end{array}$ & $\begin{array}{c}\text { Número promedio de } \\
\text { brotes / cotiledones }\end{array}$ \\
( & DE) & (土 DE)
\end{tabular}

Superficie en contacto con el medio (SCM)
ANA/BA
$1.63 \pm 0.24 \mathrm{~B}$
$1.65 \pm 0.19 \mathrm{~B}$
$2,4-D / K$
$1.44 \pm 0.20 \mathrm{~B}$
$1.77 \pm 0.18 \mathrm{~B}$

Superficie alejada del medio (SAM)
ANA/BA
$2.43 \pm 0.29 \mathrm{~A}$
$3.36 \pm 0.34 \mathrm{~A}$
$2,4-D / K$
$1.67 \pm 0.13 \mathrm{~B}$
$1.00 \pm 0.07 \mathrm{~B}$

Letras mayúsculas indican diferencias significativas entre todos los valores (tratamiento y superficie por tratamiento) $(P<0.05)$.

\section{Análisis histológico}

El estudio histológico de los explantes a distintos tiempos de cultivo mostró su origen adventicio por organogénesis directa. Si bien el patrón de desarrollo fue similar, la temporalidad de la aparición de las diferentes estructuras difirió entre los tratamientos y tipos de tejidos (cotiledones vs. hipocotilo), y fue más tardía en 2,4$\mathrm{D} / \mathrm{K}$ y en los cotiledones. Frecuentemente se observó la reactivación del meristemo apical del embrión a partir del cual se diferenció una yema apical, mientras que la cofia se hipertrofió y con el tiempo degeneró.

Los cortes longitudinales de los embriones al momento de ser sembrados (Figura 2) evidenciaron que la epidermis tiene un solo estrato de células rectangulares, aplanadas longitudinalmente, que rodean al tejido fundamental y a los haces provasculares centrales. Las 
células del tejido fundamental son parenquimáticas, cúbicas, dispuestas ordenadamente a lo largo del eje, con pocos espacios intercelulares, núcleo conspicuo, citoplasma denso; mientras que la región del tejido provascular presentó células nucleadas con forma alargada. Ambos tipos celulares contenían abundante material de reserva. El meristemo apical del brote tiene la forma característica de domo, conformado por células isodiamétricas, densamente citoplásmicas, de núcleo prominente. En esta etapa, no se observó actividad mitótica en ninguna de las regiones mencionadas.

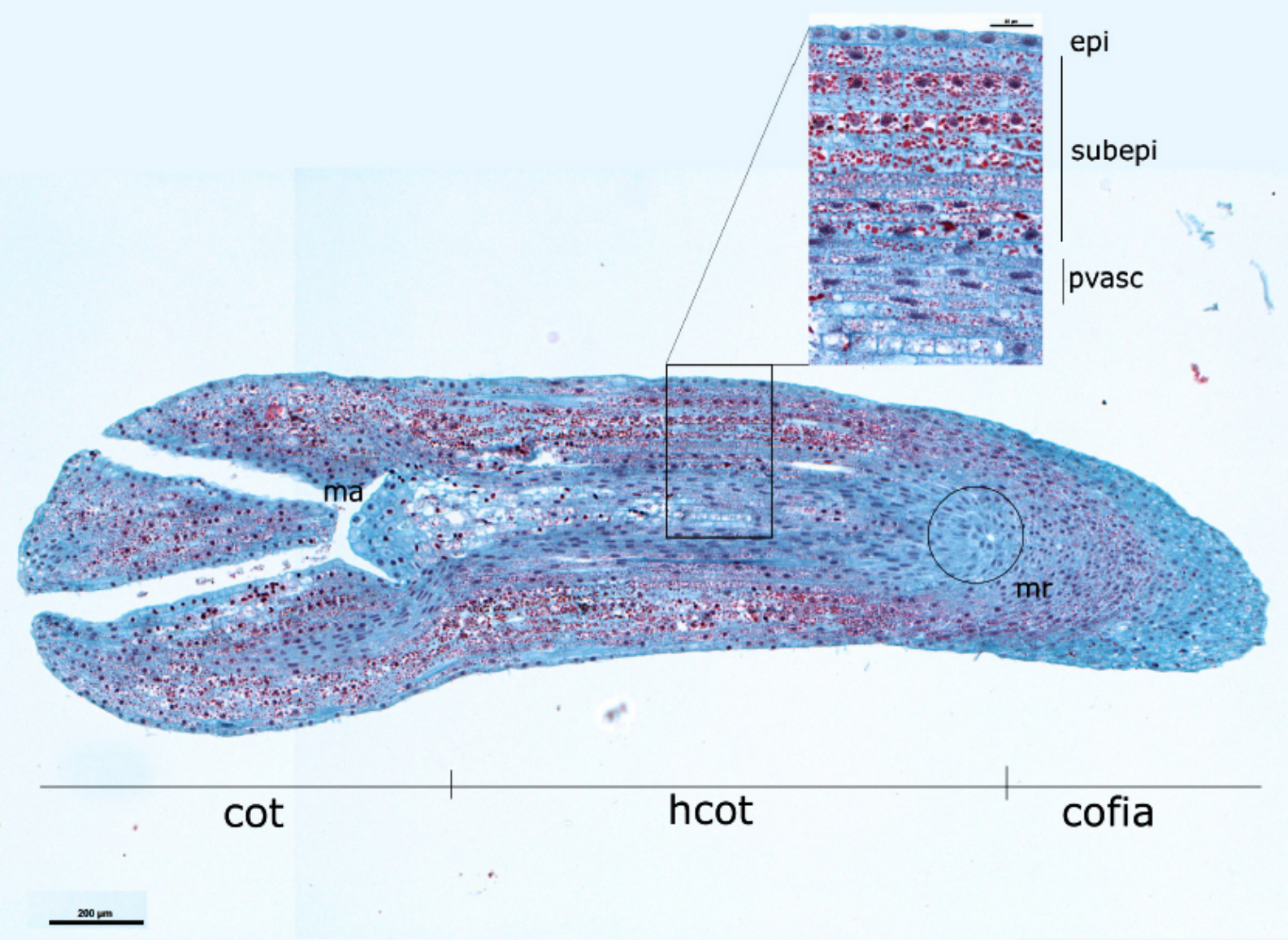

Cot = Cotiledones; hco = Hipocotilo; $\mathrm{ma}=$ Meristemo apical; $\mathrm{mr}=$ Meristemo radicular; epi $=$ Epidermis; subepi $=$ Subepidermis/tejido fundamental; pvasc $=$ Haz provascular.

Figura 2. Corte longitudinal de embrión maduro de Pseudotsuga menziesii (Mirb.) Franco y acercamiento de las capas de células que lo conforman. 
El tercer y hasta el cuarto día de cultivo se caracterizaron por la reactivación de la actividad mitótica a través del explante, con divisiones celulares anticlinales en el tejido fundamental y provascular del hipocotilo, que probablemente aportaron al alargamiento del embrión. Asimismo, se advirtió la aparición de vacuolas, así como una notoria disminución en la cantidad de material de reserva en el tejido fundamental.

Entre el cuarto y el sexto día de cultivo surgieron divisiones celulares localizadas, periclinales y anticlinales, en las capas subepidérmicas (Figura 3A) y epidérmicas (Figura 3B) del eje embrionario, principalmente en las regiones intercotiledonarias y en la región media-distal del hipocotilo. La respuesta en los cotiledones fue más lenta que en el hipocotilo y las divisiones celulares fueron dispersas.
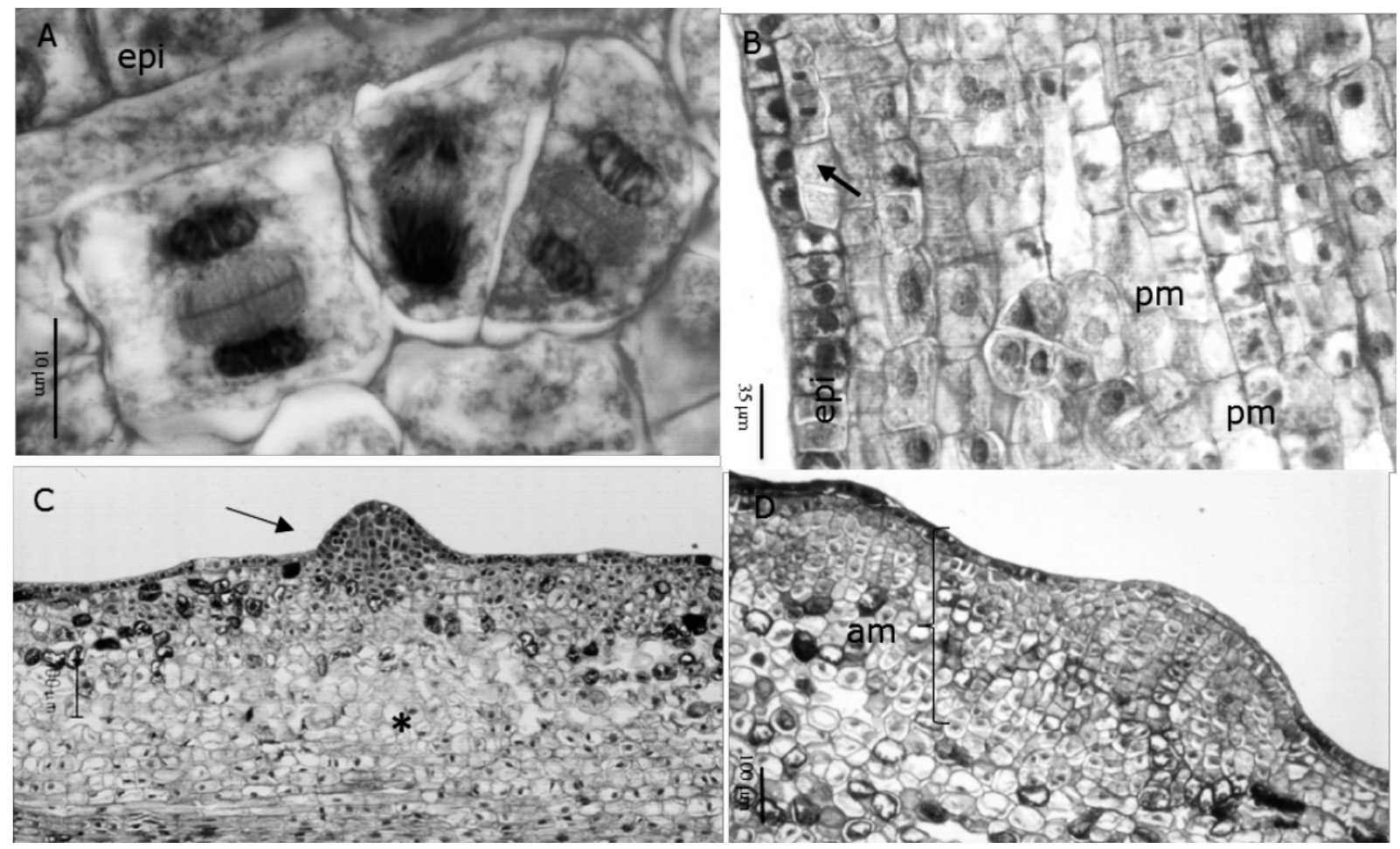

A. Formación de conjuntos de células en la capa subepidérmica a los seis días de cultivo (100X); B. Divisiones periclinales y anticlinales de la capa epidérmica (epi), así como promeristemoides (pm) en las capas subepdiérmicas (20X); C. Meristemoide en el hipocotilo de la superficie en contacto con el medio a los después de 14 días de cultivo (10X); D. Región meristemática en el hipocotilo de la superficie alejada del medio después de 16 días de cultivo (10X).

Figura 3. Análisis estructural de las etapas tempranas de la formación de brotes adventicios a partir del cultivo in vitro de embriones cigóticos maduros de Pseudotsuga menziesii (Mirb.) Franco. 
A partir del sexto día, tanto en ANA/BA como en 2,4-D/K, el patrón morfogenético varió en función de la distancia del tejido con respecto al medio de cultivo. En la SAM se evidenciaron las primeras agrupaciones celulares y promeristemoides (estructuras de 4-6 células) (Figura 3B), que se iniciaron a partir de la activación mitótica de una o muy pocas células y revelaron una distribución dispersa en el tejido fundamental. Estas estructuras se formaron primero en la región media-distal del hipocotilo y posteriormente se extendieron a los cotiledones. A partir de los 12 días en ANA/BA y de los 14 días en 2,4-D/K, se detectaron los primeros meristemoides, con forma de domo, que dieron a la superficie del embrión una apariencia nodular (Figura 3C).

La epidermis formó parte de dichas estructuras al donar células mediante divisiones anticlinales. El cuerpo de los meristemoides creció por medio de divisiones periclinales y anticlinales de células del tejido fundamental. En los cotiledones, la actividad meristemática inició después de diez días de cultivo en ANA/BA, usualmente sobre la superficie abaxial y en el extremo de los mismos; mientras que en los tratamientos con $2,4-\mathrm{D} / \mathrm{K}$, se presentó después de 16 a 22 días de cultivo y se limitó al ápice.

Por su parte, en la SCM se formaron áreas meristemáticas amplias (Figura 3D), que se caracterizaron por células pequeñas, de citoplasma denso y núcleo prominente, que se iniciaron a partir de divisiones anticlinales y periclinales de la epidermis, y de anticlinales, periclinales y oblicuas en las primeras dos capas subepidérmicas. En ANA/BA y 2,4-D/K, este patrón comenzó en la región media del hipocotilo a partir de los seis días, y después de los 10 a 12 días de cultivo en las regiones intercotiledonarias; mientras que los cotiledones respondieron tardíamente, a los 14 y 16 días en ANA/BA y 2,4-D/K, respectivamente. Después de 16 días alcanzaron un grosor de ocho a diez células y abarcaron la longitud total del embrión ( sin la cofia), dándole una apariencia irregular, aun si las células se mantuvieron relativamente organizadas y contenidas por la epidermis (Figura 4A). A partir de los 22 y hasta los 45 días de cultivo, de éstas áreas se originaron estructuras nodulares de apariencia meristemática, de cuya superficie se diferenciaron yemas apicales; aunque en la mayoría de los casos la epidermis del embrión constituyó parte de la estructura, se observaron otras, posiblemente proembriones, que emergieron a la superficie despúes de romper la epidermis (Figura 4B). 

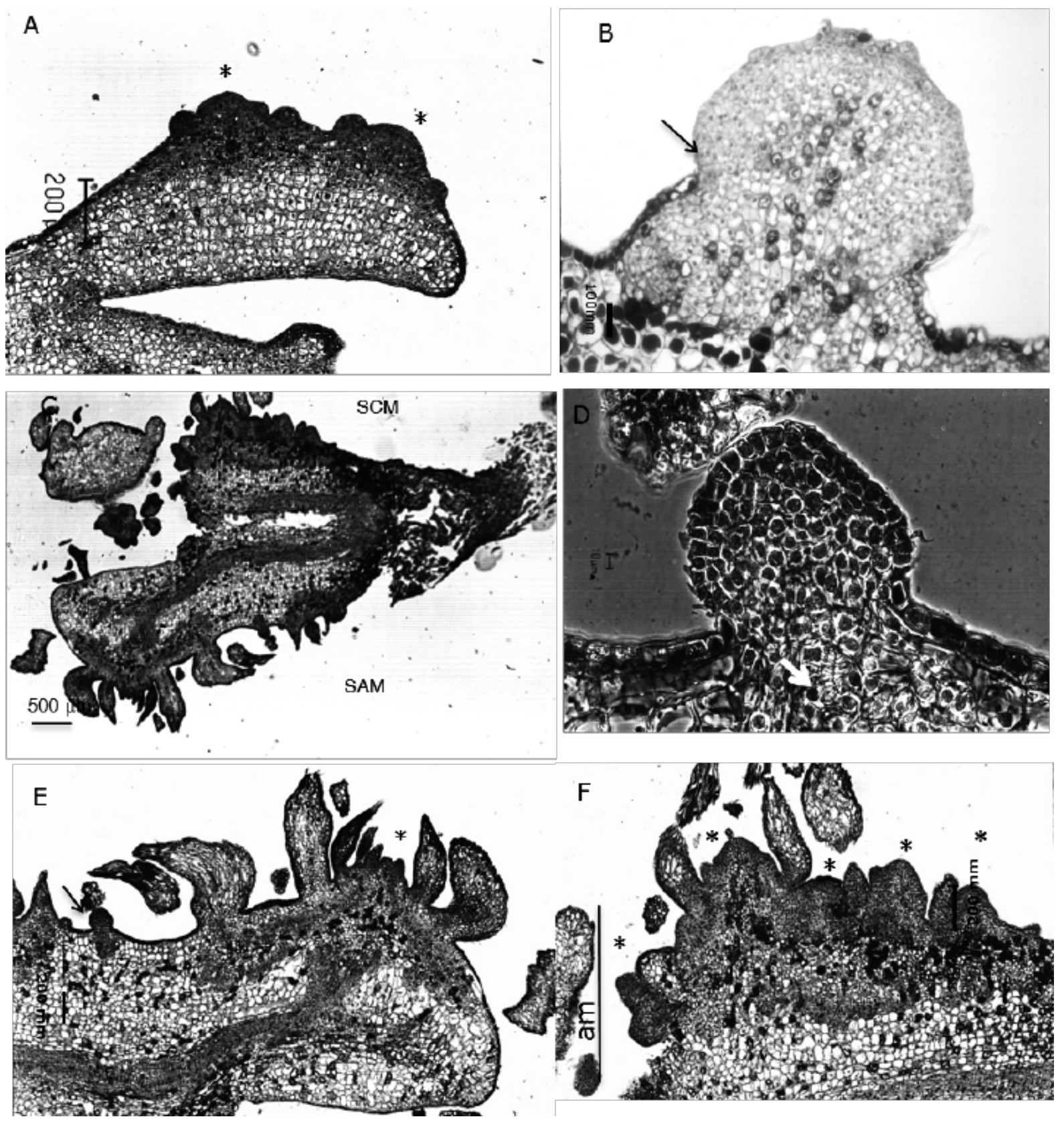

A. Primordios de brotes formados sobre cotiledones después de 30 días de cultivo (4X); B. Estructura nodular meristemática formado en la superficie del hipocotilo de la SCM después de 30 días; la flecha señala la ruptura de la epidermis (10X); C. Formación de brotes a lo largo del hipocotilo y cotiledones después de 40 días (5X); D. Nódulo meristemático mostrando la diferenciación de traqueida (flecha), Normanski 50X; E. Acercamiento de un brote formándose sobre un cotiledón en la superficie alejada del medio (SAM), así como nódulo meristemático (flecha) (10X);

F. Acercamiento de brotes formándose a partir de un área meristemática (am) de la superficie en contacto con el medio (SCM) (20X).

Figura 4. Etapas tardías del proceso de la formación de brotes adventicios a partir de embriones de Pseudotsuga menziesii (Mirb.) Franco cultivados. 
Los primeros brotes (conformados por un domo apical con primordios foliares) se distinguieron en el hipocotilo a partir de los 14 días de cultivo, aunque el proceso se generalizó entre los 20 y los 30 días en 2,4-D/K y ANA/BA, respectivamente; mientras que en los cotiledones se inició después de los 35 a los 40 días. Cortes longitudinales a los 45 días mostró que si bien muchos brotes estaban claramente diferenciados, el proceso de diferenciación fue asincrónico, particularmente en ANA/BA, ya que a esta fecha aún era posible identificar meristemoides o primordios en etapas tempranas de desarrollo, lo que prolongó el período de iniciación y el crecimiento de brotes y explica incremento notorio en número entre 90 y 130 días (Cuadro 2). En contraste, en los explantes sometidos a 2,4-D/K rara vez se evidenciaron meristemoides en etapas tardías del cultivo.

Se reconoció el inicio de brotes a partir de los nódulos meristemáticos después de los 60 días en cultivo (Figura $4 \mathrm{C}-\mathrm{F}$ ), para indicar su capacidad morfogenética. Se identificó la acumulación de taninos condensados alrededor de los meristemoides y yemas, así como la formación de novo de traqueidas asociadas, aún antes de que se evidenciaran los primordios foliares; sin embargo, rara vez se conectaron con el sistema vascular embrionario.

En el presente trabajo se advirtieron, también, los cambios celulares indicativos de la pérdida de la competencia, y por lo tanto, el comienzo de la recalcitrancia. Desde el día seis de cultivo, las células que no respondieron meristemáticamente formaron grandes vacuolas en su interior, y desplazaron al núcleo presionándolo contra la pared celular. En etapas tardías del cultivo, presentaron un arreglo laxo e irregular y la acumulación de polisacáridos en la matriz extracelular circundante, así mismo, muchas de ellas, sobre todo en la epidermis y cerca de los meristemoides y zonas meristemáticas, reunieron taninos en su interior. 


\section{Discusión}

El cultivo in vitro de embriones cigóticos completos representa una alternativa viable de propagación de genotipos mexicanos de $P$. menziesii ya que aumenta el número de brotes, y potencialmente, el número de plantas que se pueden obtener de un solo embrión. Galindo et al. (2000) indican que la organogénesis a partir de embriones de dicha especie ocurre dentro de un intervalo de concentraciones de auxinas y citocininas relativamente amplio, tanto en ANA/BA como 2,4-D/K, aunque el número de brotes, la supervivencia y la velocidad de crecimiento de los mismos difiere.

La capacidad de responder morfogenéticamente fue similar para ambos tratamientos, y se inició en los tejidos epidérmicos y subepidérmicos, tanto del hipocotilo como de los cotiledones. En general, esto contrasta con otros estudios en Pseudotsuga, en los que regularmente se utilizan cotiledones de embriones germinados in vitro como principal explante (Cheng y Voqui, 1977). Los resultados del presente trabajo demuestran que el manejo del embrión cigótico completo permite el aprovechamiento de diferentes regiones ontogenéticamente predeterminadas para el crecimiento, que mantiene a las células en estado competente y puede representar una alternativa útil para la propagación in vitro en especies o genotipos recalcitrantes.

Se confirmó que el uso de BA promovió la formación de un mayor número de brotes, aunque en el tratamiento con $\mathrm{K}$, adquirieron una apariencia más vigorosa. Datos similares se verificaron para otras especies con las cuales se comparó el efecto de diferentes tipos de citocininas sobre el crecimiento de brotes adventicios, incluyendo genotipos de P. menziesii de Estados Unidos de América (Cheng y Voqui, 1977), así como varias especies de Pinus (Pelletier y Laliberté, 2000; Montalbán et al., 2011) y Picea (López et al., 2000).

El menor número de brotes observado en 2,4-D/K después de 130 días de cultivo significa que el período durante el cual las células del explante se mantienen competentes es menor que en los cultivos de ANA/BA. Esto se corroboró con el análisis histológico, con el que se pudo evidenciar que en ANA/BA los explantes 
producen meristemoides aún en etapas tardías de cultivo. Aunque no se conocen las causas de dicha respuesta, en otros sistemas se ha consignado que la capacidad de los explantes para absorber y metabolizar citocininas varía según el tipo de regulador, el tiempo de cultivo y el desarrollo del explante (Cortizo et al. 2009), lo cual se vea probablemente también afectado por el tipo de citocinina. No se puede descartar que el empleo de 2,4-D, considerado un inductor de callo y embriogénesis, pudo influir en una pérdida más rápida de la competencia, particularmente en los cotiledones.

La formación de brotes adventicios siguió el patrón descrito (Cheah y Cheng 1978; Yeung et al., 1981; Villalobos et al., 1985; von Arnold y Grönroos, 1986; López et al., 2000) que inició con la reactivación mitótica de una o dos células que fomaron, en orden secuencial, promeristemoides, meristemoides y luego el domo apical integrado por el meristemo y los primordios foliares.

Sin embargo, la distribución espacial y la asincronía temporal del proceso morfogenético evidenció la importancia de la posición de las células con respecto al medio de cultivo para su competencia. Si bien se desarrollaron brotes tanto en la superficie alejada del medio, como en la que estaba en contacto directo con la misma, en los primeros, se iniciaron a partir de meristemoides individuales, mientras que en los segundos, en ANA/BA en particular, se formaron amplias zonas meristemáticas que diferenciaron brotes en etapas tardías del cultivo. Esto concuerda con la hipótiesis de que el establecimiento de gradientes hormonales y nutrimentales en los explantes es un factor importante en la inducción de la competencia celular y la posterior determinación organogénica (Yeung et al., 1981; Joy y Thorpe, 1999).

Según von Arnold y Grönroos (1986) las áreas meristemáticas son el resultado de la exposición supraóptima y prolongada a citocininas, por lo que la formación de meristemoides distintivos, se obtiene al reducir el tiempo de exposición a estos reguladores de crecimiento. En Pinus banksiana Lamb., se describe que las células en contacto con el medio proliferan, pero nunca dan origen a brotes (Pelletier y Laliberté, 2000), lo cual contrasta con las observaciones del presente trabajo. 
Finalmente, se probó que la mayoría de los brotes formados tuvieron un origen multicelular, ya que los meristemoides se constituyeron por células donadas por la epidermis y por la subepidermis. Esto contrasta con registros previos del desarrollo de brotes a partir de explantes de cotiledón de $P$. menziesii, con un origen subepidérmico y que emergen al romper la epidermis (Cheah y Cheng, 1978), lo que sugiere una pérdida de la competencia de la epidermis en tejido diferenciado o con mayor grado de maduración.

En el estudio realizado, la epidermis experimentó una actividad mitótica importante, con divisiones anticlinales y periclinales, que donaron células tanto a la superficie del embrión como al tejido fundamental y las regiones meristemáticas en desarrollo. Tal comportamiento se ha observado en sistemas de micropropagación propuestos para Pinus radiata D. Don (Villalobos et al, 1985), Pinus strobus L. (Flinn et al., 1988) y Abies amabilis Douglas ex Forbes (Kulchetscky et al., 1995). Aunque este tipo de reacción se estimuló con los tratamientos de inducción, es posible que también se haya facilitado por una predisposición de la epidermis a responder meristemáticamente, proceso que describió Allen (1947) en uno de los pocos trabajos publicados sobre la embriogénesis cigótica para el género. El origen multicelular de las estructuras puede tener un fuerte impacto sobre futuras estrategias de mejoramiento, particularmente si se consideran vías como la transformación genética, ya que la obtención de quimeras es altamente probable.

\section{Conclusiones}

Este trabajo hace un seguimiento del inicio y etapas tempranas de la formación de bortes adventicios a partir del cultivo de embriones cigóticos maduros completos de P. menziesii, en respuesta a los tratamientos con ANA/BA y 2,4-D/K. El análisis histológico contribuye a la comprensión de los eventos celulares que preceden la generación de nuevos órganos, así como a la pérdida de competencia morfogenética e inicio de la recalcitrancia. 
El número de brotes formados en ANA/BA es más alto que en 2,4-D/K, si bien el proceso fue más asincrónico. El análisis histológico muestra que el proceso de caulogénesis ocurre vía organogénesis directa y los brotes tienen un origen multicelular, ya que se conforman por células tanto de la epidermis como de las capas celulares subepidérmicas, lo que da lugar a zonas meristemáticas o meristemoides, según su distancia del medio de cultivo.

La pérdida de la competencia celular ocurre primero en 2,4-D/K, y el mayor número de brotes formados en ANA/BA resulta de una actividad meristemática prolongada.

Los estudios de esta índole constituyen la base de futuras investigaciones para la optimización de las técnicas de cultivo con importantes implicaciones al proveer un contexto estructural para abordar los eventos fisiológicos y moleculares que regulan la morfogénesis tanto in vitro como ex vitro.

\section{Agradecimientos}

Florencia García recibió una beca de la Dirección General de Estudios de Posgrado (DGEP) UNAM y Guadalupe Monjarás del Consejo Nacional de Ciencia y Tecnología. Este trabajo fue financiado por el Sistema de Investigación Ignacio Zaragoza (SIZA)Conacyt (970603003) y por la Fundación Produce-Tlaxcala (UAT-06). Se agradece particularmente a los revisores anónimos por su lectura y comentarios al manuscrito.

\section{Conflicto de intereses}

Los autores declaran no tener conflicto de intereses. 


\section{Contribución por autor}

Florencia García Campusano: diseño y realización de los experimentos y elaboración del manuscrito; Guadalupe Monjarás González: realización de los experimentos; Gema Galindo Flores: diseño de experimentos,y elaboración y revisión del manuscrito; Alejandro Ponce Mendoza: análisis estadísticos de resultados; Víctor Manuel Chávez Ávila: revisión del manuscrito; Judith Márquez Guzmán: diseño de experimentos y revisión del manuscrito.

\section{Referencias}

Allen, G. S. 1947. Embryogeny and the development of the apical meristems of Pseudotsuga. II. Late embryogeny. American Journal of Botany 34(2): 73-80. Doi: 10.1002/j.1537-2197.1947.tb12960.x.

Bonga, J. M. 2015. A comparative evaluation of the application of somatic embryogenesis, rooting of cuttings, and organogenesis of conifers. Canadian Journal of Forest Research 45(4): 379-383. Doi: 10.1139/cjfr-2014-0360.

Carrillo B., M. G., J. L. Rodríguez De la O y J. G. Álvarez M. 2011. Morfogénesis in vitro de Pseudotsuga menziesii var. glauca. Revista Chapingo, Serie Ciencias Forestales y del Ambiente 17(2): 273-282. Doi: 10.5154/r.rchscfa.2010.04.024.

Cheah, K. T. and T. Y. Cheng. 1978. Histological analysis of adventitious bud formation in cultured Douglas-fir cotyledon. American Journal of Botany 65: 845849. Doi: $10.2307 / 2442179$.

Cheng, T. Y. and T. H. Voqui. 1977. Regeneration of Douglas-fir plantlets through tissue culture. Science 198(4314): 306-307. Doi: 10.1126/science.198.4314.306. 
Cortizo, M., C. Cuesta, M. L. Centeno, A. Rodríguez, B. Fernández and R. Ordás. 2009. Benzyladenine metabolism and temporal competence of Pinus pinea cotyledons to form buds in vitro. Journal of Plant Physiology 166(10): 1069-1076. Doi: $10.1016 / j . j p l p h .2008 .12 .013$.

Durzan, D. J. and P. K. Gupta. 1987. Somatic embryogenesis and polyembriogenesis in Douglas-fir cell suspension cultures. Plant Science 52(3): 229235. Doi: $10.1016 / 0168-9452(87) 90056-2$.

Flinn, B. S., D. T. Webb and W. Newcomb. 1988. The role of cell clusters and promeristemoids in determination and competence for caulogenesis by Pinus strobus cotyledons in vitro. Canadian Journal of Botany 66(8): 1556-1565. Doi: $10.1139 / \mathrm{b} 88-214$.

Galindo F., G., F. García C., G. Monjarás G. y V. M. Chávez Á. 2000. Regeneración in vitro de Pseudotsuga macrolepis Flous a partir de embriones maduros. Investigación para el Desarrollo Regional. SEP-CONACYT. México, D. F., México. pp. 165-169.

Gugger, P. F., A. González, H. Rodríguez, S. Sugita and J. Cavender B. 2011. Southward Pleistocene migration of Douglas-fir into Mexico: phylogeography, ecological niche modeling and conservation of 'rear edge' populations. New Phytologist 189:1185-1199. Doi: 10.1111/j.1469-8137.2010.03559.

Gupta, P. K. and D. J. Durzan. 1985. Shoot multiplication from mature trees of Douglas-fir (Pseudotsuga menziesii) and sugar pine (Pinus lambertiana). Plant Cell Reports 4(4): 177-179. Doi: 10.1007/BF00269282.

Hermann, R. K. and D. P. Lavender. 1990. Pseudotsuga menziesii (Mirb.) Franco: Pinaceae. In: Russel, M. B.and B. H. Honkala (eds.) Silvics of North America. Vol 1: Conifers. Agriculture Handbook 654. Vol.1. USDA Forest Services. Washington D.C., USA. pp. 527-540. 
Joy, R. W. and T. A. Thorpe. 1999. Shoot morphogenesis: structure, physiology, biochemistry and molecular biology. In: Soh, W. and S. S. Bhojwani (eds.). Morphogenesis in plant tissue cultures. Springer. The Netherlands. pp. 171-214.

Juárez A., A., J. López U., J. J. Vargas H. and C. Sáenz R. 2006. Geographic variation in germination and initial seedling growth of Pseudotsuga menziesii of México. Agrociencia 40: 783-792.

Kulchetscky, L., I. S. Harry, E. C. Yeung and T. A. Thorpe. 1995. In vitro regeneration of Pacific silver fir (Abies amabilis) plantlets and histological analysis of shoot formation. Tree Physiology 15(11): 727-738. Doi: 10.1093/treephys/15.11.727.

López, A. L., L. P. Olguín, J. Márquez, V. M. Chávez and R. Bye. 2000. Adventitious bud formation from mature embryos of Picea chihuahuana Martínez, an endangered Mexican spruce tree. Annals of Botany 86(2): 921-927. Doi: 10.1006/anbo.2000.1257

Mápula, L., M., R. Bonilla y D. A. Rodríguez. 1996. Germinación y crecimiento inicial de Pseudotsuga macrolepis Flous en Chapingo, México. Revista Chapingo: Ciencias Forestales 5: 111-117.

Montalbán, I. A., N. De Diego and P. Moncaleán. 2011. Testing novel cytokinins for improved in vitro adventitious shoots formation and subsequent ex vitro performance in Pinus radiata. Forestry 84(4): 363-373. Doi: 10.1093/forestry/cpr022.

Pelletier, G. and S. Laliberté. 2000. Effect of embryo orientation on the developmental sequence of adventitious organogenesis in jack pine (Pinus banksiana Lamb). Canadian Journal of Botany 78(10): 1348-1360. Doi: 10.1139/b00-105

R Development Core Team. 2011. R: A language and environment for statistical computing. R Foundation for Statistical Computing. Vienna, Austria. http://www.R-project.org. 
Schenk, R. U. and A. C. Hildebrandt. 1972. Medium and techniques for induction and growth of monocotyledonous and dicotyledonous plant cell cultures. Canadian Journal of Botany 50(1): 199-204. Doi: 10.1139/b72-026.

Secretaría de Medio Ambiente y Recursos Naturales (Semarnat). 2010. Norma Oficial Mexicana NOM-059-SEMARNAT-2010. Protección ambiental-Especies nativas de México de flora y fauna silvestres-Categorías de riesgo y especificaciones para su inclusión, exclusión o cambio-Lista de especies en riesgo. 30 de diciembre de 2010. Diario Oficial de la Federación. México, D.F., México. 40 p.

Vargas, J. J., J. López U., V. J. Reyes, A. Domínguez and M. Mápula. 2004. Natural populations of Douglas- fir in Mexico: current status and needs for conservation. In: Beaulieu J (ed.). Silviculture and the conservation of genetic resources for sustainable forest management. In: Proceedings of the symposium of the North American Forest Commission: forest genetic resources and silviculture working groups, and the International Union of Forest Research Organizations (IUFRO). Quebec City, QC, Canada. pp. 26-36.

Velasco G., M. V., J. López U., G. Ángeles P., J. J. Vargas H. and V. Guerra-de la C. 2007. Pseudotsuga menziesii seed dispersion in populations of central Mexico. Agrociencia 41:121-131.

Villalobos, V. M., E. C. Yeung and T. A. Thorpe. 1985. Origin of adventitious shoots in excised radiata pine cotyledons cultured in vitro. Canadian Journal of Botany 63(12): 2172-2176. Doi: 10.1139/b85-307

von Arnold, S. and R. Grönroos. 1986. Anatomical changes and peroxidase activity after cytokinin treatments inducing adventitious bud formation on embryos of Picea abies. Botanical Gazette 147(4): 425-431. Doi: 10.1086/337610

Winton, L. L. and S. A. Verhagen. 1977. Shoots from Douglas-fir cultures. Canadian Journal of Botany 55 (9): 1246-1250. Doi: 10.1139/b77-144 
Yeung, E. C., J. Aitken, S. Biondi and T. A. Thorpe. 1981. Shoot histogenesis in cotyledon explants of radiate pine. Botanical Gazette 142:494-501.

Doi: $10.1086 / 337251$.

Zavala C., F. y J. T. Méndez M. 1996. Factores que afectan la producción de semillas en Pseudotsuga macrolepis Flous. en el Estado de Hidalgo, México. Acta Botánica Mexicana 36: 1-13. Doi: 10.21829/abm36.1996.756.

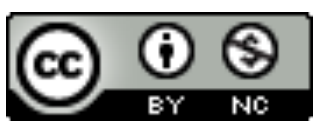

Todos los textos publicados por la Revista Mexicana de Ciencias Forestales -sin excepción- se distribuyen amparados bajo la licencia Creative Commons 4.0 Atribución-No Comercial (CC BY-NC 4.0 Internacional), que permite a terceros utilizar lo publicado siempre que mencionen la autoría del trabajo y a la primera publicación en esta revista. 